Portland State University

PDXScholar

\title{
The Development of an Art Practice: Reflecting on My Experiences in the Undergraduate Art Programs at Clackamas Community College and Portland State University
}

Justin M. Taylor

Portland State University

Follow this and additional works at: https://pdxscholar.library.pdx.edu/honorstheses

Part of the Art Practice Commons

Let us know how access to this document benefits you.

\section{Recommended Citation}

Taylor, Justin M., "The Development of an Art Practice: Reflecting on My Experiences in the Undergraduate Art Programs at Clackamas Community College and Portland State University" (2020). University Honors Theses. Paper 852.

https://doi.org/10.15760/honors.873

This Thesis is brought to you for free and open access. It has been accepted for inclusion in University Honors Theses by an authorized administrator of PDXScholar. Please contact us if we can make this document more accessible: pdxscholar@pdx.edu. 
The Development of an Art Practice: Reflecting on My Experiences in the Undergraduate Art Programs at Clackamas Community College and Portland State University

by

Justin Taylor

An undergraduate honors thesis submitted in partial fulfillment of the requirements for the degree of

Bachelor of Science

in

University Honors

and

Art Practices

Thesis Adviser

David Andersen

Portland State University 


\section{Abstract}

In this essay, I will be discussing the content and overall experience of my bachelorette thesis exhibition, The Development of an Art Practice, on display at the Alexander Gallery, Oregon City, Oregon, from November $6^{\text {th }}$ through December $6^{\text {th }} 2019$. The exhibition showcased my development in the undergraduate art practice programs at Clackamas Community College, and Portland State University. Featured in the exhibition was a selection of two-dimensional visual works, which I produced in the programs.

My work was process driven with an emphasis on experimentation. While the selection of work revealed reoccurring themes, both in process and content, this happened instinctually. My focus was on exploring combinations of compositional techniques, mediums, processes and content; utilizing texture, imagery, color and form to convey ideas and feelings. My goal was to develop formal strategies in visual communication, working with two-dimensional representation and abstraction.

In addition to the art works, was an interactive element, in which I invited visitors of the gallery, as well as some colleagues and my advisor, to paint with me, and engage in conversation about visual art, culture and the ideas contained in the exhibition. The interactive studio space was modeled after the academic studios that I used in the programs (figure 1.) It consisted of two sets of easels, chairs and tables. In this space, I revisited years of accumulated sketchbooks and drawings. I also painted and developed conversations with guest artists, gallery visitors, students and instructors. 


\section{Exhibition Process}

The Alexander gallery was key in realizing the exhibition. The biggest challenge in constructing exhibition, was balancing the interactive space with the display space. What made this possible was the gallery itself, due to its size and layout. It allowed me to divide the gallery in two distinct and comfortable spaces.

Mounting the exhibition required consideration and planning. I developed several floorplan sketches prior to mounting the show. The sketching process helped me understand and strategize how the viewer would experience the space.

The show space was the first thing the viewer saw when they entered the gallery. The mounting was rooted in a traditional method of displaying two-dimensional visual art, but it utilized some experimental interventions. 10 medium-large-scale works (24x24"-48x60") were hung on the walls in a usual fashion, but another 14 small-scale works, (6x9"-8x10") on panels, were laid flat on podiums, and leaned up against the walls (figure 2.)

This combination of traditional and experimental methods added another layer to the visual experience, one which echoed the art works themselves, resulting in increased cohesion in the exhibition overall. The interventions also helped with balancing out and integrating the interactive studio space, which might otherwise have been too distracting. The paintings were all placed intentionally, to help lead the view around the gallery, and eventually allow the viewer to discover the interactive space.

Upon discovering the interactive studio space, I wanted the viewer to feel invited, so a large opening was provided to the space. My easel and chair were angled to allow them to see 
what I was working on as soon as they discovered the space. I would verbally invite the viewer to watch, paint, or share their thoughts on my painting process and the show.

While I did spend a significant amount of time in the gallery alone, reflecting on my work, the realization of the project depended on the participation of visitors. Critical conversation was a large part of my experiences in the programs which I wanted to incorporate, as I moved through the reflective process. One of my goals in the project was to continue the development of conversations around art, academia and culture.

The majority of the exhibition I designed and mounted myself, but I did receive the help from my advisor, David Andersen and the gallery director, Kate Simmons. They both assisted me in lighting the works, publicizing the exhibition and with gallery up keep. The mounting required minimal tools and technologies. I achieved it with the use of ladders, a hammer, some nails, and levels. A large wooden false wall was all I used to divide the gallery space from the interactive studio space. It was overall a simple process.

\section{Creative Process, Materials and Methods}

My processes, techniques and materials were rooted in combination of experimentalism and tradition. Traditional techniques, methods and materials were my anchor for various experimental ideas. It was my goal to develop a basis of skills and experiences in a variety of media, with the intention that I would develop a personalized set of tools for visually communicating my thoughts and ideas.

I decided to anchor myself in two-dimensional visual art because I wanted a constraint, as I experimented with color, form, content and process. Mixed media provided the largest 
range of possibilities to work with, within this constraint. It provided a range of speed, texture, surface quality and contrast. I worked primarily with acrylic paint, oil stick, oil pastel, collage, digital editing, graphite and charcoal.

My process varied with each batch of experiments. Sometimes I would begin with imagery and push it towards abstraction, and other times I went the opposite direction. There were some processes however, which I frequently utilized in the experimentation process.

Photos were a significant part of my process (figure 3.) I collected and surrounded my creative space with photo reproductions of art works, objects, people, surfaces, environments, and plants. Some photos I found online or in books and some I took myself. Sometimes I used photo reproductions of my own works in other works (figure 4.) Photos could be used as a source of inspiration, as reference and as collage elements. Collage was one way I was able to speed up the production of experimentation. I could cut out and adhere an image to a setting which saved me the time of rendering the image.

Digital sketching was another process which helped me in the overall experimentation process. I could begin by working instinctually, applying color, form, imagery and texture to a surface without thinking. Nearing the completion of the piece however, I would capture a digital photo of it and manipulate it in Photoshop. This process allowed me to visualize and fine tune compositions with minimal labor and resources (figure 5.)

While formal experimentation did lead to several discoveries, it also limited some aspects of my work. Predictability of the outcome suffered, as well as the coherence of my overall body of work. Sacrificing these aspects however, led to more potential for developing a 
breadth of techniques and styles. It is my hope to develop a custom style of conveying ideas, feelings and meaning which is best suited to the content of my work. While I did not develop a personalized process which I am confident in, I did lay the foundation to achieve that in the future.

Resources and References

Due to my context and my sensibilities, my work takes influence from several different artists, movements and styles. Regular research and exposure to art was a significant aspect of my development. Being in the art programs at CCC, and PSU, there was a constant exposure to art work.

It was a requirement for nearly all art students to study art history, contemporary art, the work of our colleagues and work in the local galleries. I found the exposure to be an irreplaceable form inspiration. The exposure encouraged me to develop my own ideas and it informed me on a variety of creative processes, and sensibilities.

I have not made a strong connection with any single artist or movement. I studied over 500 visual artists over the course of the program, and I gained inspiration from nearly every one of them. The plethora of influence combined with my openness to experiment, and an active appreciation for different styles with their accompanying philosophies has led to an ambiguous, influential energy which manifests in my work.

Having such an ambiguous understanding of the artistic traditions, materials and strategies which I explored in my own work, has led to some anxiety. Moving forward I will be spending more time analyzing my work, to identify the traditions and strategies I am 
employing. I believe this will strengthen my understanding of the tools which I am utilizing, helping me communicate my ideas and feelings with more accuracy and efficiency.

\section{Reflection}

The exhibition was a success overall, in that it helped me develop a deeper understanding of my undergraduate experience, and my sensibilities as an artist. Flipping through hundreds of sketchbook pages, observing the selection of work in solitude, and listening to the thoughts of several other artists, students and instructors, all helped me understand my decision-making process and instincts.

Often under a strict time constraint, with a high volume of work to produce, I had to act instinctually with little time for planning and forethought. By the time I began to develop momentum in a particular direction the quarter would end and I would have to start over. Moving through the program at this pace and rhythm resulted in a body of work which helped me understand trends in my instinctual thinking and creation process.

I was encouraged to observe my surroundings with a keen and sensitive mind and to think critically about context, form and function. I now consider a much greater perspective than I did before starting the program. Where I once was unaware of how political context, technologies and resources might have influenced a work of art, I am now engaged in this kind of questioning. I also communicate with much more consideration, for both the content of my ideas, and the way in which they are conveyed. After many failed attempts to communicate, I 
now realize that imagery, objects, form and color can carry with them implied meanings and associations, which all impact the way a viewer might interpret a visual work.

In reflection I understand that my ability and willingness to explore was my greatest strength in the program. I set out with the challenge to open myself to as many styles, theories and processes as possible. This resulted in a wider range of mark making, technical processes and content at my disposal. Due to the range of exploration, my ability to develop a concentrated understanding of any particular style, process or knowledge of content was limited. Now that I have had time to explore, I plan on restricting my range so that I can develop a deeper understanding of a few styles and processes which I will use to explore focused and specific content.

Moving forward with my practice, I will continue to employ imagery and abstraction to communicate ideas, feelings and perspectives, as I develop a deeper understanding of my environment through reading, conversation and observation. It is my goal to find possibilities to alter the condition of my surroundings through creative interventions. While I will continue to develop two-dimensional visual works, I am thinking about integrating my background in construction and engineering, to develop three-dimensional, interactive works. I am also interested in a more socially integrated practice, and moving into the realm of public spaces. Years from now I envision myself engaged in collaborative ideas that have a greater impact on my community. 


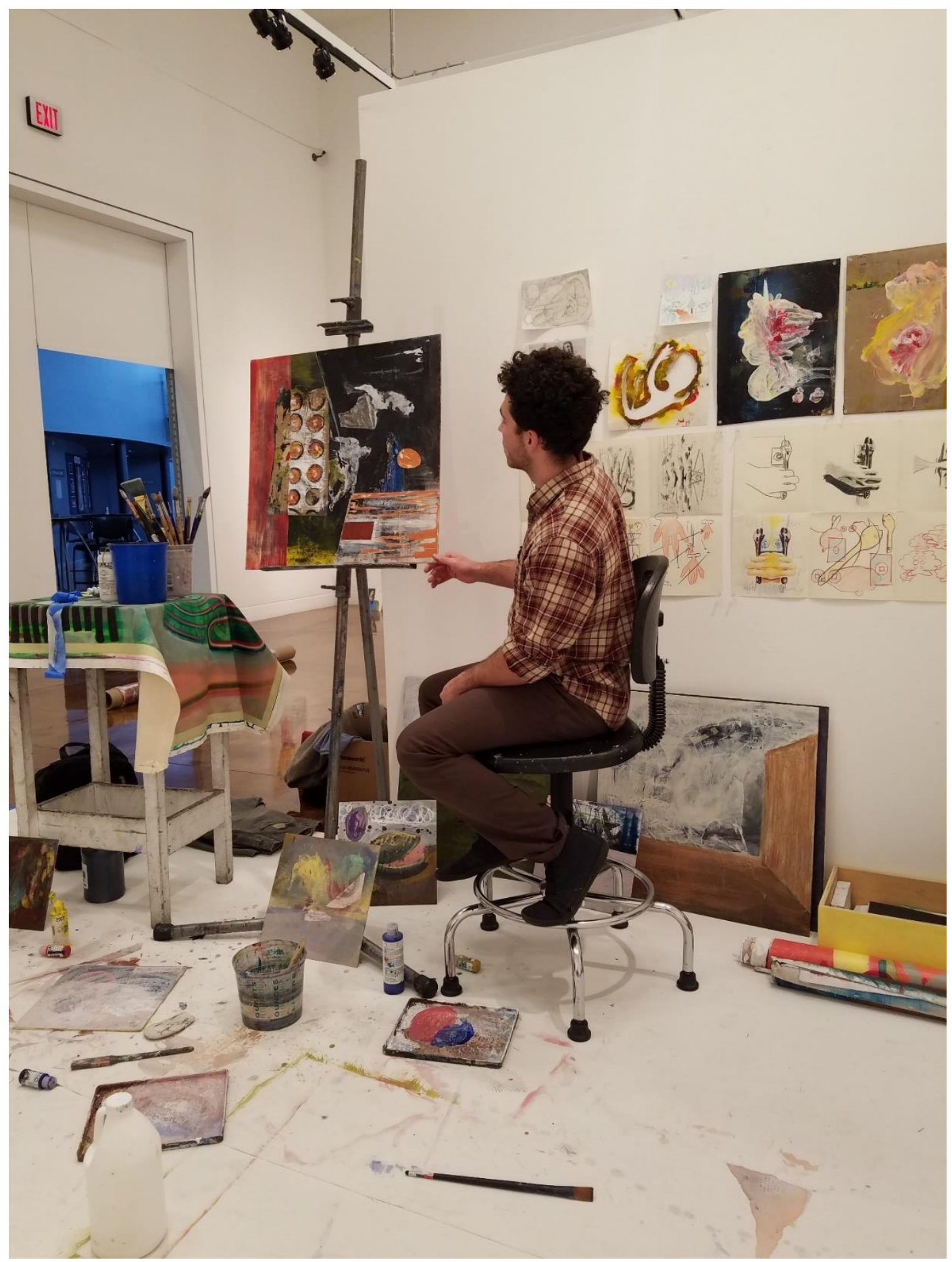

Figure 1.

Justin Taylor with works in progress, Alexander Gallery, Clackamas Community College, Oregon City, Oregon. 2019. 


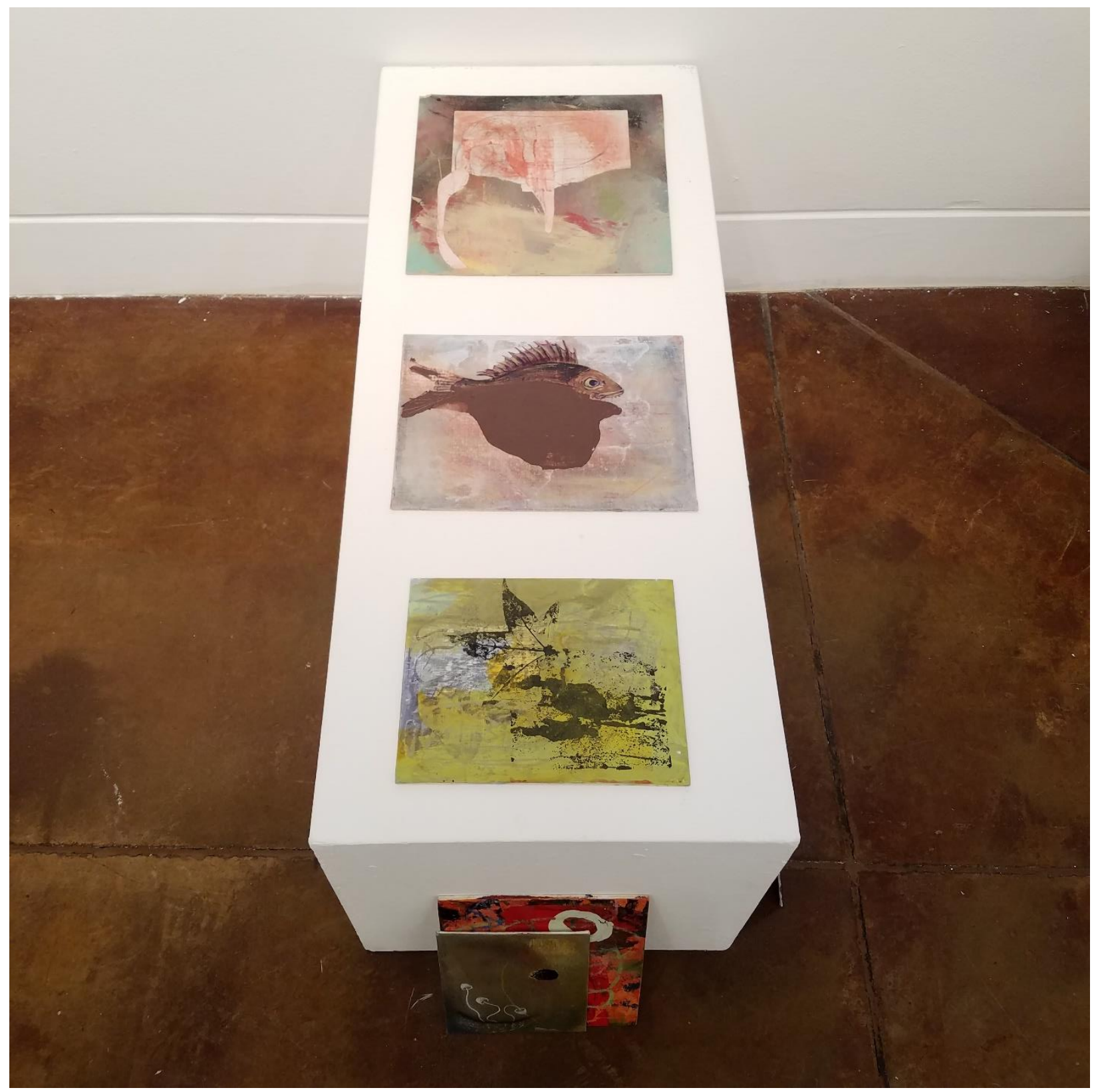

Figure 2.

Untitled Works from different batches of experiments, 2017-2019. 


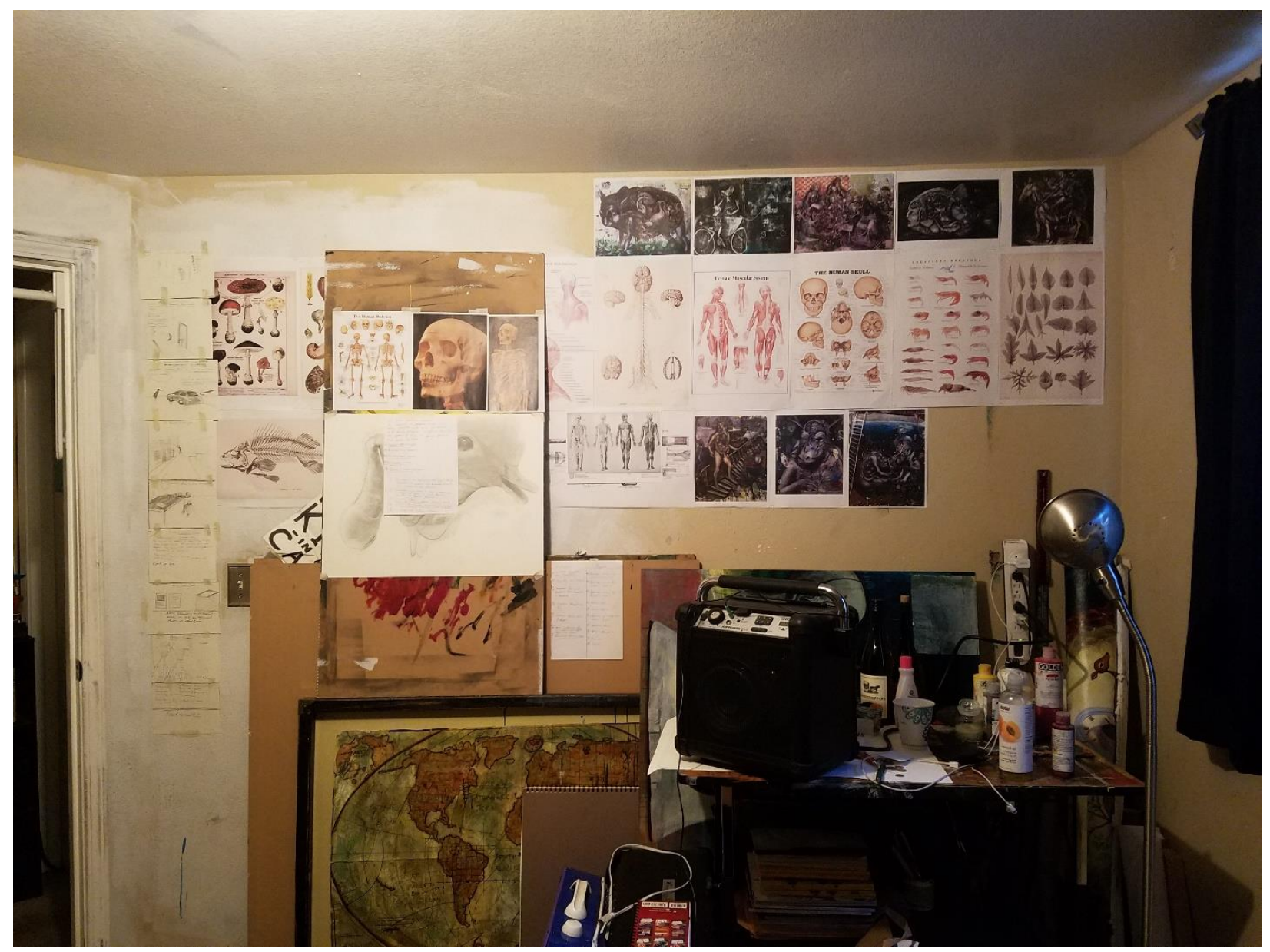

Figure 3.

Clackamas studio space. (showing use of photo references,) Clackamas, Oregon. 2018. 


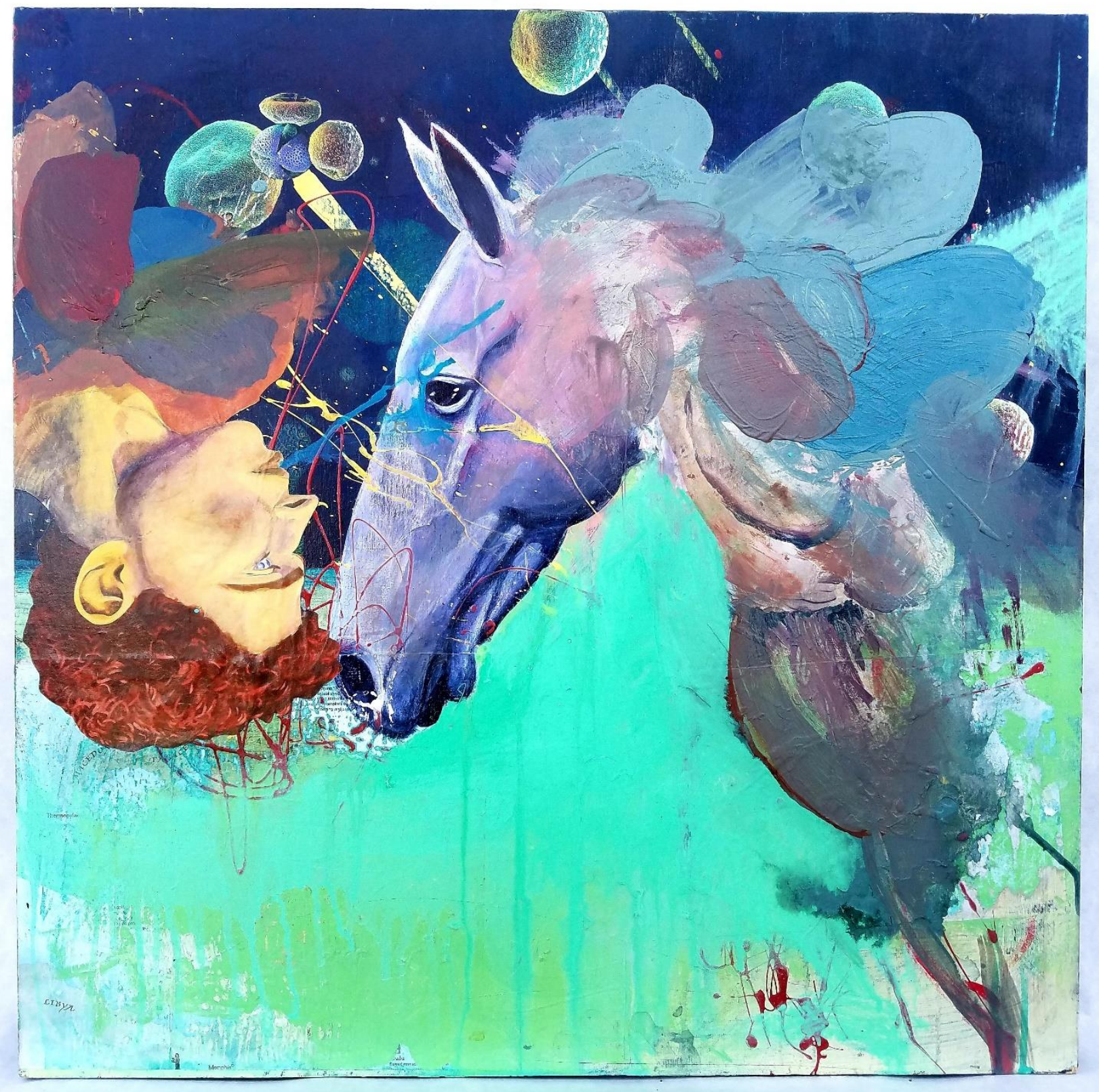

Figure 4.

Justin Taylor, Spit in the Horse's Eye, 2019. Mixed media on panel, 24x24”

The inverted self-portrait in this piece, is a collage element from a photo reproduction of painting that I made for a series of self-portraits. 

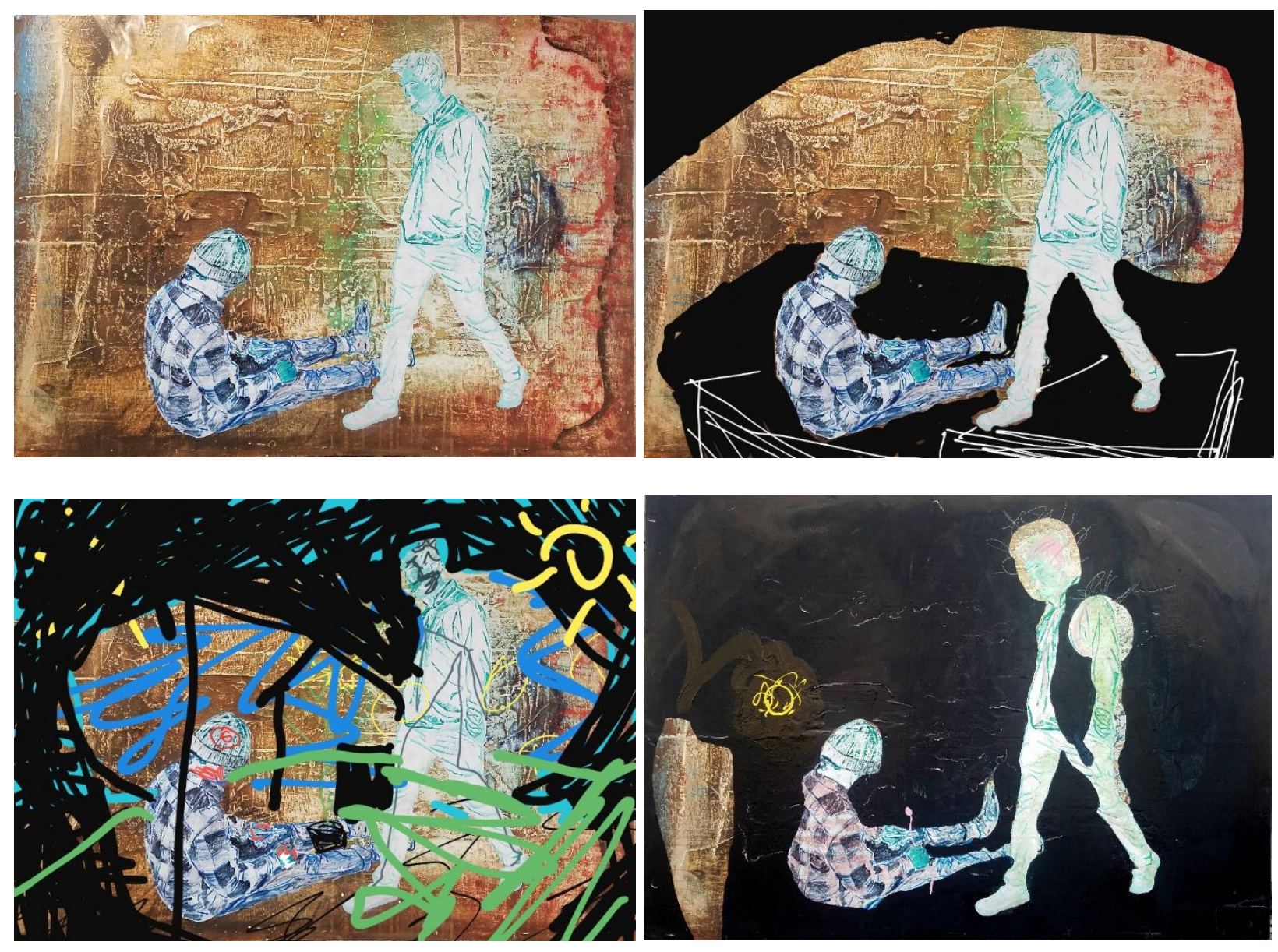

Figure 5.

Justin Taylor, Sauvie Island Fungus, 2019. Mixed media on panel, 36x48”

Top left: Sauvie Island Fungus, prior to digital sketching. Top right: digital sketch 1.

Bottom left: digital sketch 2. Bottom right: final version of Sauvie Island. 